\title{
Stress perfusion cardiac MRI with regadenoson and gadofoveset trisodium
}

\author{
Bradley D Allen ${ }^{1 *}$, Neil Chatterjee ${ }^{1}$, Jad Bou Ayache ${ }^{1}$, Benjamin H Freed ${ }^{2}$, Daniel C Lee ${ }^{2}$, Timothy Carroll', \\ Michael Markl ${ }^{1,3}$, Jeremy D Collins', James C Carr ${ }^{1}$ \\ From 18th Annual SCMR Scientific Sessions \\ Nice, France. 4-7 February 2015
}

\section{Background}

Stress perfusion cardiac MRI (CMR) with a high relaxivity blood-pool contrast agent should allow for improved quantification of myocardial perfusion and myocardium blood volume in patients with coronary artery disease (CAD). In the current study, we sought to evaluate the diagnostic performance and image quality of stress perfusion CMR using the intravascular contrast agent gadofoveset trisodium and regadenoson stress agent in patients with suspected CAD.

\section{Methods}

Patients with suspected CAD were identified based on referral for cardiac catheterization and/or stress testing and recruited to undergo CMR at 1.5T (MAGNETOM Avanto, Siemens, Erlangen, Germany). The CMR protocol included stress perfusion imaging using $5 \mathrm{ml}$ intravenous (IV) regadenoson (Lexiscan, Astellas US LLC) as the stress agent, and the effects of regadenoson were reversed with $50 \mathrm{mg}$ IV aminophylline following the completion of stress imaging. Left ventricular (LV) base, mid, and apex short axis cine images were acquired in identical slice positions during first pass using $5 \mathrm{ml} \mathrm{IV}$ gadofoveset trisodium contrast (Ablavar, Lantheus) at both stress and rest. Perfusion images were reviewed and sensitivity and specificity for CAD diagnosis were calculated. Overall image quality, image noise, and presence of artifact for each patient scan were graded on a scale of 1 - poor to 5 - excellent.In addition to the perfusion scan, the MRI protocol included pre- and postcontrast 2D Modified Look-Locker (MOLLI) measurement of T1 which were used to calculate the myocardial blood volume (in $\mathrm{ml} / 100 \mathrm{~g}$ of tissue).

\section{Results}

Stress perfusion CMR was performed on $\mathrm{n}=20$ subjects (age: $61.8 \pm 12.2$ years, M:F = 13:7). Seventeen patients (85\%) had cardiac catheterization within 1 month of CMR, while 2 patients had a positive nuclear stress test, and 1 patient had positive stress echocardiography. Seven catheterized patients (41\%) had $\geq 70 \%$ occlusion of at least one of the left anterior descending, left circumflex, or right main coronary artery. The sensitivity/ specificity for diagnosing CAD on a per-patient basis was $0.8 / 0.5$. Qualitative assessment revealed good image quality ( $4.38 \pm 0.46)$, low noise (4.45 \pm 0.28$)$, and little artifact (4.28 \pm 0.38 ).For pre-/post- stress perfusion MRI in our cohort, the average $\Delta \mathrm{R}_{1}{ }^{\mathrm{myo}}$ was $1.23 \pm 0.24 \mathrm{msec}^{-}$ ${ }^{1}$ while the average $\Delta \mathrm{R}_{1}{ }^{\text {blood }}$ was $3.63 \pm 0.54 \mathrm{msec}^{-1}$. As shown in figure 1 , the slope of the linear regression between $\Delta \mathrm{R}_{1}{ }^{\text {myo }}$ and $\Delta \mathrm{R}_{1}{ }^{\text {blood }}$ was a $=0.34$ suggesting that gadofoveset trisodium does not behave as a true intravascular agent in the myocardium.

\section{Conclusions}

Stress perfusion CMR using regadenoson and gadofoveset trisodium provides diagnostic quality images with sensitivity for CAD diagnosis comparable to published results. Our results suggest that gadofoveset trisodium does not behave as a true intravascular agent in the myocardium and thus a quantification of myocardial intravascular blood volume (and hence a calculated coronary flow reserve) cannot be calculated using the approach.

\section{Funding}

Research support for this study was provided by Astellas US LLC.

${ }^{1}$ Radiology, Northwestern University, Chicago, IL, USA

Full list of author information is available at the end of the article 


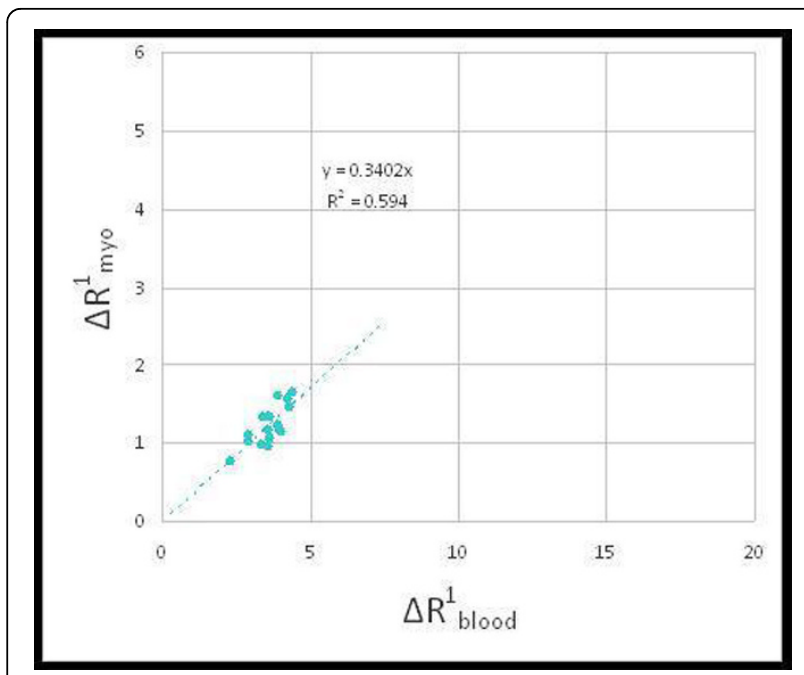

Figure 1

\section{Authors' details}

'Radiology, Northwestern University, Chicago, IL, USA. ${ }^{2}$ Medicine-Cardiology, Northwestern University, Chicago, IL, USA. ${ }^{3}$ Biomedical Engineering,

Northwestern University, Chicago, IL, USA.

Published: 3 February 2015

\section{doi:10.1186/1532-429X-17-S1-P113}

Cite this article as: Allen et al: Stress perfusion cardiac MRI with regadenoson and gadofoveset trisodium. Journal of Cardiovascular Magnetic Resonance 2015 17(Suppl 1):P113.

Submit your next manuscript to BioMed Central and take full advantage of:

- Convenient online submission

- Thorough peer review

- No space constraints or color figure charges

- Immediate publication on acceptance

- Inclusion in PubMed, CAS, Scopus and Google Scholar

- Research which is freely available for redistribution

Submit your manuscript at www.biomedcentral.com/submit 